\title{
Cold Stress and Cholinergic Supersensitivity
}

To the Editor:

In the rat (adult male Sprague-Dawley) chronic forced swim stress (Dilsaver et al. 1986) and chronic inescapable footshock (Dilsaver and Alessi 1987) induce marked supersensitivity to the hypothermic effects of the muscarinic cholinergic agonist oxotremorine. These observations are consistent with a report that immobilization of $10 \mathrm{~min}$ duration activates the septohippocampal muscarinic cholinergic pathway as evidenced by augmentation of the high affinity choline uptake and increased release of acetylcholine (Gilad et al. 1985). However, Brunello et al. (1981) reported that the exposure of rats to an ambient temperature of $4^{\circ} \mathrm{C}$ actually reduced the rate of acetylcholine turnover within the hypothalamus. Furthermore, the concentration of acetylcholine was reduced within the hypothalamus after $24 \mathrm{hr}$ of exposure, and choline content decreased within the frontal cortex, hippocampus, and hypothalamus. The incorporation of choline into acetylcholine was also reduced within $1 \mathrm{hr}$ of cold room exposure in these regions. This parameter returned to control levels within $24 \mathrm{hr}$ in the cortex and hippocampus, but not within the hypothalamus. The severity of cold stress was increased by wetting the animals' fur, immobilizing them, and lowering the ambient temperature to $0^{\circ} \mathrm{C}$. A majority of animals died within $45 \mathrm{~min}$ under these conditions. These effects of cold exposure were apparently not the consequence of a nonspecific response, as they did not occur if the animals were merely immobilized.

We wish to report the effects of chronic exposure of rats to an ambient temperature of $4^{\circ} \mathrm{C}$. In this study, we measured the sensitivity of a muscarinic mechanism to the hypothermic effects of oxotremorine relative to baseline (i.e., the prestress response).

Telemetric thermosensors (Mini-Mitter Co., Sun River, OR) were implanted in the peritoneal cavity, The use of these devices has been described elsewhere (Tocco-Bradley 1985; Dilsaver et al. 1987). Oxotremorine challenges were conducted before and after 1 and 4 weeks of cold exposure. Challenges were preceded by the injection of methylscopolamine nitrate, $1 \mathrm{mg} / \mathrm{kg}$ ip, to block the peripheral effect of a muscarinic agonist. Baseline temperature was measured $30 \mathrm{~min}$ later. Oxotremorine (base), $0.25 \mathrm{mg} /$ $\mathrm{kg}$, was then given and temperature recorded every $10 \mathrm{~min}$ for $120 \mathrm{~min}$. The animals were exposed to cold by placing them in individual cages in a temperature-controlled room with an ambient temperature of $4^{\circ} \mathrm{C}$, and kept on a 12 -hr light/dark cycle. Data were analyzed using the Student's paired $t$-test. The mean hypothermic response of each animal at baseline was paired with its response after I and 4 weeks of cold room exposure. Data are available on 9 animals for the first week of exposure and 8 (owing to instrument failure) for 4 weeks of cold exposure.

The mean hypothermic response at baseline (prior to cold room exposure) was $0.56 \pm 0.16^{\circ} \mathrm{C}$ (mean \pm SEM) versus $0.70 \pm 0.27^{\circ} \mathrm{C}$ after 1 week of cold room exposure (NS; $t=0.37, \mathrm{df}=8$ ). Following the fourth week of cold room exposure, the animals exhibited a mean hypothermic response of $0.54 \pm 0.37^{\circ} \mathrm{C}(\mathrm{NS}, t=0.32, \mathrm{df}=7)$.

In this experiment, chronic cold room exposure for 1 or 4 weeks failed to produce supersensitivity to the hypothermic effects of oxotremorine. This contrasts with the capacity of chronic forced swim and inescapable footshock to produce enhanced sensitivity to the thermic effects of this muscarinic agonist. The negative finding in this study is in accordance with a report that cold exposure decreases the turnover ratc and synthesis of acetylcholine within particular pain regions. Cold exposure is accompanied by increased thermogenesis (Jansky 1979), and it is conceivable that the negative findings reported here are a consequence of a compensatory response to cold stress itself. That is, various forms of stress may indeed tend to produce supersensitization of cholinergic mechanisms, but cold stress in particular may offset the capacity of cholinergic agonists to produce thermic blunting due to an increased capacity to maintain body temperature.

Steven C. Dilsaver

Robin K. Davidson

Department of Psychiatry

University of Michigan

Ann Arbor, MI 48109-1687 


\section{References}

Brunello N, Tagramonte A, Cheney DL, Coster E (1981); Effects of immobilization and cold exposure on the turnover rate of acetylcholine in rat brain areas. Neuroscience 6:1759-1764.

Dilsaver SC, Snider RM, Alessi NE (1986): Stress induces supersensitivity of a cholinergic system in rats. Biol Psychiatry 21:1093-1096.

Dilsaver SC. Snider RM. Alessi NE (1987): Amitriptyline supersensitizes a central cholinergic mechanism. Biol Psychiatry 22:495-507.

Dilsaver SC, Alessi NE (1987): Chronic inescapable footshock produces cholinergic system supersensitivity. Biol Psvchiatry (to be published).
Gilad GM, Mahon BD. Finkelstein Y, Koffler B, Gilad VH (1985): Stress induced activation of the hippocampal cholinergic system and the pituitary adrenal axis. Brain Res 347:404-408.

Jansky L (1979): Heat production. In Lomex P. Schonbaum E (eds), Body Temperature Regulation, Drug Effects and Therapeutic Implications. New York: Marcel Dekker, pp 119-127.

Tocco-Bradley R. Kluger MJ, Kauffman CH (1985): Effect of age on fever: An acute phase response of rats to endotoxin and Salmonella typhimurium. Infert Immun 47:106-14. 